\title{
MET alterations detected in blood-derived circulating tumor DNA correlate with bone metastases and poor prognosis
}

\author{
Sadakatsu Ikeda ${ }^{1,2^{*}}$, Maria Schwaederle ${ }^{1 *}$, Mandakini Mohindra' ${ }^{1}$ Denis L. Fontes Jardim ${ }^{3}$ and Razelle Kurzrock ${ }^{1 *}$
}

\begin{abstract}
Background: We analyzed clinical associations of MET alterations in the plasma of patients with diverse malignancies.

Methods: Digital sequencing of circulating tumor DNA (ctDNA) (54-70 genes) was performed in 438 patients; 263 patients also had tissue sequencing (182-315 genes). The most represented tumor types were gastrointestinal (28.1\%), brain (24.9\%), and lung (23.2\%). Most patients (71.2\%) had recurrent/metastatic disease.

Results: MET alterations were observed in 31 patients $(7.1 \%)$ and correlated with bone metastasis $(P=0.007)$, with TP53 $(P=0.001)$ and PTEN $(P=0.003)$ abnormalities, and with an increased number of alterations (median, 4 vs 1, $P=0.001)$ (all multivariable analyses). Patients with MET alterations demonstrated a significantly shorter median time to metastasis/recurrence (1.0 vs 10.4 months, $P=0.044$, multivariable) and a poorer survival (30.6 vs 58.4 months, $P=0.013$, univariate only). Of the 31 patients with MET alterations, 18 also had tissue testing; only two also had tissue MET alterations (11.1\%); MET alterations were detected at a lower frequency in tissue (1.14\%) compared to ctDNA (7.1\%), with $P=0.0002$.

Conclusions: In conclusion, the detection of MET alterations by liquid biopsy is feasible. MET ctDNA alterations were associated with a poorer prognosis, higher numbers of genomic abnormalities, and bone metastases. The correlation with bone metastases may explain the higher frequency of MET alterations in blood ctDNA than in tissue (since bones are rarely biopsied) and the previous observations of bone-predominant responses to MET inhibitors. The high number of co-altered genes suggests that MET inhibitors may need to be combined with other agents to induce/ optimize responses.
\end{abstract}

Keywords: MET, ctDNA, cfDNA, Liquid biopsies, Bone metastasis

\section{Background}

MET, also called c-MET or hepatocyte growth factor (HGF) receptor, is a receptor tyrosine kinase discovered as an oncogene in the 1980s $[1,2]$. Independent research found that HGF or scatter factor (SF) was a ligand for MET [3]. Upon binding of HGF to MET, the kinase domain phosphorylates growth factor receptor-bound protein 2 (GRB2) and GRB2-associated binding protein 1 (GAB1) and activates diverse downstream signaling pathways important in cancer, including the ERK/

\footnotetext{
*Correspondence: saikeda@ucsd.edu; mschwaederle@ucsd.edu; rkurzrock@ucsd.edu

'Department of Medicine, Center for Personalized Cancer Therapy, Division of Hematology/Oncology, University of California, San Diego, Moores Cancer Center, 3855 Health Sciences Drive, \#0658, La Jolla, CA 92093-0987, USA Full list of author information is available at the end of the article
}

MAPK, PI3K-Akt/PKB, Crk-Rap, and Rac-Pak pathways [4]. These pathways form distinct branches that interact to regulate cell proliferation, invasion, migration, angiogenesis, development, organ regeneration, and tumorigenesis [4].

Activating $M E T$ mutations are found in diverse human cancer [5]. For instance, activating mutations in the kinase domain are a feature of both hereditary and some non-hereditary forms of papillary renal cell carcinoma [6]. MET amplification is seen in 5 to $20 \%$ of non-small cell lung cancer (NSCLC) and gastric cancer [7]. MET overexpression correlates with poor treatment outcome in some malignancies [8].

Drugs that target MET include inhibitors of the HGF/ -MET pathway, MET antibodies, and MET kinase 
inhibitors [8]. Cabozantinib and crizotinib are both Food and Drug Administration (FDA)-approved multikinase inhibitors that are also potent suppressors of MET $[9,10]$. Crizotinib induced responses in some patients with highly $M E T$-amplified lung cancer [11]. Studies with the multi-target MET inhibitor cabozantinib have shown significant activity against a variety of solid tumors including melanoma, as well as renal and non-small cell lung, liver, medullary thyroid, breast, and ovarian cancer, but this activity is likely due to other targets of cabozantinib, such as VEGFR or RET [9]. In the phase I setting, patients with $M E T$ amplification did not respond to MET inhibitors (but the number of treated patients was small) [5].

Because of their non-invasive nature, liquid biopsies are increasingly used in the clinical setting. Indeed, numerous studies showed a relatively good correlation with tissue sequencing and the potential to detect actionable alterations [12-16]. In this study, we analyzed MET alterations in the plasma-derived circulating tumor DNA (ctDNA) of 438 patients with diverse malignancies and explored the relationship between $M E T$ alterations, demographics, as well as other molecular alterations and clinical outcomes.

\section{Methods}

\section{Patients}

We reviewed the clinicopathology and clinical outcomes of 438 consecutive patients with cancer for whom ctDNA testing had been performed and who were seen at the UC San Diego Moores Cancer Center from June 2014 to July 2016. Pathology was reviewed at UCSD. Data was abstracted from the electronic medical record. This study was performed and consents were obtained in accordance with the UCSD Institutional Review Board guidelines [PREDICT-UCSD (Profile Related Evidence Determining Individualized Cancer Therapy); NCT02478931].

\section{Next-generation sequencing}

Digital sequencing of ctDNA (DNA) in all patients was performed by Guardant Health, Inc. (Guardant360, Redwood City, California, http://www.guardanthealth.com/guardant360/), a Clinical Laboratory Improvement Amendment (CLIA)-certified and College of American Pathologists (CAP)-accredited clinical laboratory. The analytical and clinical validation of Guardant360 was conducted in accordance with evidentiary standards established by the Standards for Reporting of Diagnostic Accuracy (STARD), REporting of tumor MARKer Studies (REMARK), Evaluation of Genomic Applications in Practice and Prevention (EGAPP), and the recent Next-generation Sequencing: Standardization of Clinical Testing (Nex-StoCT) biomarker guidelines [17]. As described in Lanman et al. [17], 5-30 ng of ctDNA was isolated from plasma (two $10 \mathrm{ml}$ Streck tubes drawn for each patient) and sequencing libraries were prepared with custom in-line barcode molecular tagging and complete sequencing at $15,000 \times$ read depth $(\sim 4000$ unique double-stranded cfDNA fragments, each represented by $3-5$ sequencing reads). The panels utilize hybrid capture followed by NGS of the critical exons in a panel of 54-70 genes (Additional file 1: Table S1 to S3) and report all four major types of genomic alterations (point mutations, indels, fusions, and copy number amplifications). Post-sequencing bioinformatics matches the complementary strands of each barcoded DNA fragment to remove false positive results [17]. The variant allele fraction (VAF) is computed as the number of mutated DNA molecules divided by the total number (mutated plus wild type) of DNA fragments at that allele; VAF is reported as a percentage. The majority of cell-free DNA is wild type (germline); thus, the median VAF of somatic alterations is $<0.5 \%$. The analytic sensitivity reaches detection of one to two single-mutant fragments from a $10-\mathrm{ml}$ blood sample (0.1\% limit of detection), and the analytic specificity is greater than $99.9999 \%$ [17].

For 144 patients, a 54-gene panel was used, which identified potential tumor-related alterations in 54 cancer-related genes (Additional file 1: Table S1) including copy number amplifications in ERBB2, EGFR, and $M E T$ (indels and fusions were not detected as part of this panel). For 272 patients, a 68-gene version of the original panel (expanded to all four major alteration types) was used, and for 22 patients, the most recent 70-gene panel version (further expanded to amplifications in 18 genes and fusions in 6 genes) was applied (Additional file 1: Table S2 and S3). Only non-synonymous alterations were included in our analysis.

In addition, 263 patients $(\sim 60 \%)$ of the 438 patients with ctDNA test also had CLIA/CAP-accredited next-generation sequencing (NGS) performed on tumor tissue (FoundationOne ${ }^{\mathrm{Tw}}$, Cambridge, Massachusetts, http:// www.foundationone.com.) ( $N=182$ to 315 gene panels).

\section{Statistical and outcome analysis}

Patient characteristics were summarized using descriptive statistics. Medians and respective 95\% confidence intervals and range were calculated, whenever possible. Associations between categorical variables were tested using a binary logistic regression model. Linear variables were tested using the Mann-Whitney $U$ test for univariable analyses and a multiple linear regression model for multivariable analyses.

Time to metastasis/recurrence was defined as the time interval between diagnosis and first metastasis/recurrence (whichever came first) or last follow-up date (patients who had not recurred/developed metastases at last follow-up were censored on that date). Overall survival (OS) was defined as the time from diagnosis to 
death or last follow-up date for patients who were alive (patients still alive at the last follow-up were censored on that date). Estimations for the time to first metastasis/recurrence and OS were done using Kaplan-Meier analyses and were compared among subgroups by the log-rank test for univariable analysis or Cox regression models for multivariable analysis. All statistical analyses were performed by author MS with SPSS version 24.0.

\section{Results}

\section{Patient demographic characteristics}

The median age of patients at diagnosis was 57.5 years (CI 95\%, 54.5-59.1). Women comprised 52.1\% $(N=228)$ of the population. The majority of patients were Caucasian $(69.2 \%, N=303)$. The most represented tumor types were gastrointestinal $(28.1 \%, N=123)$, brain $(24.9 \%, N=109)$, lung $(23.2 \%, N=102)$, and breast $(11.6 \%, N=51)$ cancers. The majority of the patients had recurrent or metastatic disease at the time of blood draw used for testing $(71.2 \%$, $N=312)$ (Table 1).

MET alterations and associations with patient characteristics Overall, MET alterations were observed in 31 of the 438 patients whose ctDNA was tested (7.1\%). Sixteen patients had a $M E T$ amplification only; 13 had a somatic mutation only; and two had both an amplification and a somatic MET mutation (Fig. 1a).

\section{Univariate analyses}

$M E T$ alterations were significantly (positively) associated with lung cancers $(11.8 \%)$ and the presence of metastasis/recurrence at the time of blood draw and negatively

Table 1 Demographics comparison of 438 patients with or without MET alterations

\begin{tabular}{|c|c|c|c|c|}
\hline Characteristics & $\begin{array}{l}\text { Total patients, } \\
N=438(100 \%)\end{array}$ & $\begin{array}{l}\text { MET wild type, } \\
N=407 \text { (92.9\%) }\end{array}$ & $\begin{array}{l}\text { MET alteration(s), } \\
N=31(7.1 \%)\end{array}$ & $P$ values* \\
\hline Age at diagnosis (years) (median, Cl 95\%) & $57.5(54.5-59.1)$ & $57.7(55.3-59.2)$ & $53.8(49.0-62.2)$ & 0.791 \\
\hline Gender & & & & 0.288 \\
\hline Women & $228(52.1 \%)$ & $209(91.7 \%)$ & $19(8.3 \%)$ & \\
\hline Men & $210(47.9 \%)$ & $198(94.3 \%)$ & $12(5.7 \%)$ & \\
\hline \multicolumn{5}{|l|}{ Ethnicity } \\
\hline Caucasian & $303(69.2 \%)$ & $284(93.7 \%)$ & $19(6.3 \%)$ & 0.326 \\
\hline Asian & $52(11.9 \%)$ & $46(88.5 \%)$ & $6(11.5 \%)$ & 0.188 \\
\hline Hispanic & $30(6.8 \%)$ & $28(93.3 \%)$ & $2(6.7 \%)$ & 0.928 \\
\hline African American & $9(2.1 \%)$ & $8(88.9 \%)$ & $1(11.1 \%)$ & 0.637 \\
\hline Middle Eastern & $5(1.1 \%)$ & $5(100 \%)$ & $0(0 \%)$ & 0.998 \\
\hline Unknown & $39(8.9 \%)$ & $36(92.3 \%)$ & $3(7.7 \%)$ & 0.875 \\
\hline \multicolumn{5}{|l|}{ Type of cancer } \\
\hline Gastrointestinal & $123(28.1 \%)$ & $118(95.9 \%)$ & $5(4.1 \%)$ & 0.132 \\
\hline Brain & 109 (24.9\%) & 107 (98.2\%) & $2(1.8 \%)$ & $0.026^{* *}$ \\
\hline Lung & $102(23.2 \%)$ & 90 (88.2\%) & $12(11.8 \%)$ & $0.039^{* *}$ \\
\hline Breast & $51(11.6 \%)$ & 45 (88.2\%) & $6(11.8 \%)$ & 0.172 \\
\hline Genitourinary & 18 (4.1\%) & 15 (83.3\%) & $3(16.7 \%)$ & 0.120 \\
\hline Head and neck & $10(2.3 \%)$ & $9(90.0 \%)$ & $1(10.0 \%)$ & 0.717 \\
\hline Gynecologic & 7 (1.6\%) & $6(85.7 \%)$ & $1(14.3 \%)$ & 0.465 \\
\hline Melanoma & $5(1.1 \%)$ & $4(80.0 \%)$ & $1(20.0 \%)$ & 0.285 \\
\hline Hematologic & $3(0.7 \%)$ & $3(100 \%)$ & $0(0 \%)$ & 0.998 \\
\hline Other $^{\mathrm{a}}$ & $10(2.3 \%)$ & 10 (100\%) & $0(0 \%)$ & 0.998 \\
\hline \multicolumn{5}{|c|}{ Presence of metastasis or recurrence at the time of blood draw } \\
\hline Yes & $312(71.2 \%)$ & $284(91.0 \%)$ & $28(9.0 \%)$ & $0.024^{* *}$ \\
\hline No & $126(28.8 \%)$ & $123(97.6 \%)$ & $3(2.4 \%)$ & \\
\hline
\end{tabular}

The percentages on the first column are expressed over the total number of patients $(N=438)$; for the second and third columns, percentages are expressed over the total number of patients for each variable

a Lymphoma $(n=2)$, sarcoma $(n=2)$, thymoma $(n=2)$, desmoid tumor, neurofibromatosis, peripheral nerve sheath tumor, and carcinoma of unknown primary (each $n=1$ ) * $P$ values were computed using the independent sample Mann-Whitney $U$ test for linear variables (age at diagnostic) and the logistic binary regression analysis for categorical variables, as appropriate

**MET alterations were negatively associated with brain tumors but positively associated with lung tumors and metastasis or recurrence at the time of blood draw 


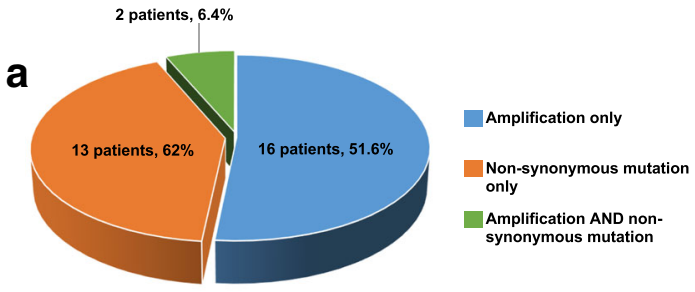

b Overall Survival $(n=438)$

Time to first metastasis/recurrence $(n=438)$

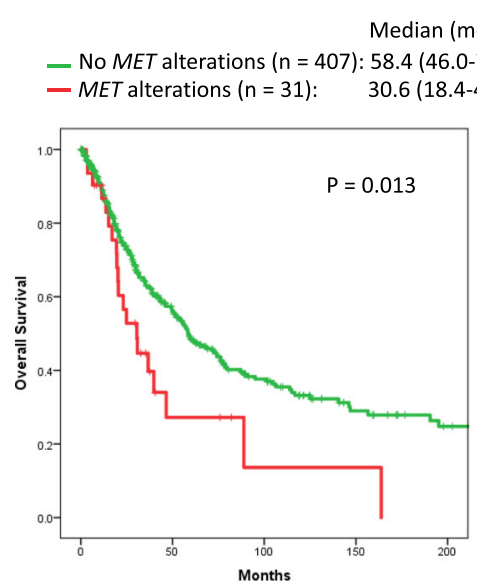

Median (months) $(95 \% \mathrm{CI})$

- No MET alterations $(n=407): 10.4(6.9-14.0)$ - MET alterations $(n=31): \quad 1.0(--)$

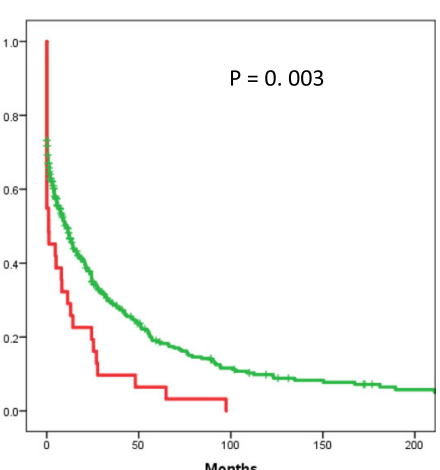

Fig. 1 a MET alterations representation. Pie chart representing the different types of MET alterations identified in our cohort comprising 438 patients. b Overall survival and time to first metastasis/recurrence. Kaplan-Meier curves depicting the overall survival (left panel) and the time to first metastasis/ recurrence (both from diagnosis time). $P$ values are from univariable analysis. For more details, refer to Tables 4 and 5

associated with brain tumors $1.8 \%$ (all $P<0.05$ ) (Table 1 ). We then examined the associations with other genomic alterations and found that $M E T$ alterations correlated in univariable analysis with alterations in TP53, EGFR, PIK3CA, BRAF, ARID1A, ALK, and PTEN genes (all $P<$ 0.05 , Additional file 1: Table S4). We also investigated the potential associations between $M E T$ alterations and the location of metastatic sites and showed a significant correlation with lymph nodes and bone metastasis (both $P<0.02$, Additional file 1: Table S4). Of note, patients with $M E T$ alterations had a median of two metastatic sites versus a single site for patients without $M E T$ alterations $(P=0.001)$. The latter conclusions remained unchanged if the patients with brain tumors, lymphoma/ leukemia, thymoma, and NF were excluded, with $P$ values of $<0.05$ for association between $M E T$ alterations and lymph node or bone metastases and increased number of metastases.

\section{Multivariate analyses}

In the multiple logistic regression model (that included any parameters that were significant $(P \leq 0.05)$ in univariate analysis), the only variables that remained statistically associated with MET alterations were aberrations in TP53 $(P=0.001)$ and PTEN $(P=0.003)$ genes, as well as an increased incidence of bone metastasis $(P=0.007)$ (Table 2$)$.
The univariate association between $M E T$ alterations and lung cancer, the negative association with brain tumors, and the correlation with metastases at the time of blood draw did not remain significant in multivariate analysis. Multivariable analysis also demonstrated that $M E T$ alterations correlated with an increased number of alterations (median of 4 alterations vs $1, P=0.001$ ) (Table 3 ). These conclusions remained valid if the patients with brain tumors, lymphoma/leukemia, thymoma, and NF were excluded, with $P$ values of $<0.01$ for association between MET alterations and TP53 or PTEN alterations, bone metastases, and increased number of metastases.

The other variables that were significantly associated with a higher number of alterations in the multivariable analysis were alterations in TP53, PIK3CA, BRAF, KRAS, or $M Y C$ genes as well as the presence of metastasis in the lymph node or adrenal tissue (Table 3).

\section{MET alterations and survival outcomes Overall survival}

Overall, 213 patients $(213 / 438,48.6 \%)$ had died at the time of our analysis (20/31 with MET alterations; 193/ 407 without $M E T$ alterations detected in their ctDNA). A log rank test demonstrated a poorer survival (time from diagnosis until death or last follow-up date) for patients bearing $M E T$ alterations (30.6 months vs 58.4, 
Table 2 Multivariable analysis of the variables associated with MET alterations*

\begin{tabular}{|c|c|c|c|c|c|c|c|c|}
\hline \multirow[b]{2}{*}{ Characteristics } & \multirow{2}{*}{$\begin{array}{l}\text { MET wild type, } \\
N=407\end{array}$} & \multirow{2}{*}{$\begin{array}{l}\text { MET altered, } \\
N=31\end{array}$} & \multicolumn{3}{|c|}{ Univariable } & \multicolumn{3}{|c|}{ Multivariable } \\
\hline & & & Wald & Odds ratio (Cl 95\%) & $P$ value & Wald & Odds ratio (Cl 95\%) & $P$ value \\
\hline \multicolumn{9}{|l|}{ Type of cancer } \\
\hline Brain $(n=109)^{* *}$ & $107(26.3 \%)$ & $2(6.5 \%)$ & 4.94 & $0.19(0.05-0.83)$ & $0.026^{* *}$ & - & - & - \\
\hline Lung $(n=102)$ & $90(22.1 \%)$ & $12(38.7 \%)$ & 4.26 & $2.22(1.04-4.76)$ & 0.039 & - & - & - \\
\hline $\begin{array}{l}\text { Presence of metastasis or recurrence } \\
\text { at the time of blood draw }(n=312)\end{array}$ & $284(69.8 \%)$ & $28(90.3 \%)$ & 5.13 & $4.0(1.2-14.3)$ & 0.024 & - & - & - \\
\hline \multicolumn{9}{|l|}{ Genetic alteration type } \\
\hline $\operatorname{TP53}(n=149)$ & $129(31.7 \%)$ & $20(64.5 \%)$ & 12.2 & $3.85(1.82-8.33)$ & $<0.001$ & 10.9 & $3.7(1.7-8.3)$ & 0.001 \\
\hline$E G F R(n=53)$ & $43(10.6 \%)$ & $10(32.4 \%)$ & 11.2 & $4.0(1.79-9.1)$ & 0.001 & - & - & - \\
\hline PIK3CA $(n=42)$ & $35(8.6 \%)$ & 7 (22.6\%) & 5.93 & $3.1(1.25-7.7)$ & 0.015 & - & - & - \\
\hline$B R A F(n=27)$ & $22(5.4 \%)$ & $5(16.1 \%)$ & 5.14 & $3.3(1.2-10.0)$ & 0.023 & - & - & - \\
\hline ARID1A $(n=19)$ & $15(3.7 \%)$ & $4(12.9 \%)$ & 5.14 & $3.85(1.2-12.5)$ & 0.023 & - & - & - \\
\hline $\operatorname{ALK}(n=14)$ & $11(2.7 \%)$ & $3(9.7 \%)$ & 3.94 & $3.85(1.02-14.3)$ & 0.047 & - & - & - \\
\hline $\operatorname{PTEN}(n=9)$ & $6(1.5 \%)$ & $3(9.7 \%)$ & 7.72 & $7.1(1.7-33.3)$ & 0.007 & 9.12 & $11.1(2.3-50.0)$ & 0.003 \\
\hline \multicolumn{9}{|l|}{ Metastatic sites } \\
\hline Lymph node $(n=139)$ & $123(30.2 \%)$ & $16(51.6 \%)$ & 5.77 & $2.4(1.2-5.3)$ & 0.016 & - & - & - \\
\hline Bone $(n=102)$ & $88(21.6 \%)$ & $14(45.2 \%)$ & 8.26 & $2.9(1.4-6.3)$ & 0.004 & 7.34 & $2.9(1.35-6.25)$ & 0.007 \\
\hline No metastases $(n=147)^{* *}$ & $145(35.6 \%)$ & $2(6.5 \%)$ & 7.96 & $0.13(0.03-0.5)$ & $0.005^{* *}$ & - & - & - \\
\hline
\end{tabular}

The Wald statistics test the unique contribution of each variable; the higher the Wald statistics, the higher the association/contribution in the model *Only variables that were significant in the univariable models (logistic regression) were included in the multivariable analysis, with the final model containing only significant covariates in the multivariable analyses (forward stepwise selection model)

**"Brain tumors" and "no metastases" were negatively associated with MET alterations in univariate analysis. These variables were not significant in the final multivariate analysis model

$P=0.013)$. In the multivariable analysis, only lung cancer as well as the presence of ARID1A, KRAS, ALK, and MYC alterations and liver metastasis remained significant predictors of a poorer survival (all $P<0.50$, Fig. 1b) (Table 4).

\section{Time to metastasis/recurrence}

Patients with $M E T$ alterations had a significantly shorter median time to metastasis/recurrence, with a median of 1.0 months (95\%CI could not be computed) versus 10.4 months (95\%CI 6.9-14.0) $(P=0.003)$ (Table 5). $M E T$ alterations remained significantly associated with a shorter time to metastasis/recurrence in a multivariable analysis $(P=0.044)$, along with the presence of liver $(P=0.022)$ or lymph node metastases $(P<0.001)$. Inversely, breast cancer correlated with a longer time to metastasis/recurrence $(P<0.001)($ Fig. $1 \mathrm{~b}$ and Table 5$)$.

\section{Comparison with tissue testing}

As noted, 438 patients had ctDNA testing; 263 of these patients also had tissue NGS performed.

Of the 31 patients with $M E T$ alterations in ctDNA, 18 also had tissue testing (Foundation Medicine see the "Methods" section). The median time interval between the blood draw and the tissue biopsy for these 18 patients was 6.1 months (95\% CI (2-13.7); range (0.2-32.6)). In most of the patients with both types of testing, the ctDNA test was performed after the tissue testing (16/18 cases). Only two patients who had a $M E T$ alteration identified in their ctDNA also had a $M E T$ alteration found in their tissue testing (11.1\%; MET amplification and MET Y501C, one patient each). In these two patients, the time interval between the ctDNA and tissue biopsies was 1.8 and 15.3 months, and both tissues used for the testing were from the primary tumor.

In only one patient, a $M E T$ amplification was detected in the tissue and not in ctDNA (1 of 263 total patients who had NGS tissue testing). The tissue test was performed on a pancreatic tumor that was surgically removed, and the ctDNA test was done more than 1 year later (recent scans showed appearance of new pulmonary and liver nodules 2 months prior the ctDNA testing).

Overall, MET alterations were detected at a significantly lower frequency in tissue (3/263 patients, $1.14 \%)$ compared to ctDNA (31/438, 7.1\%), $P=0.0002$. Further, of eight patients who harbored $M E T$ alterations in ctDNA, and had ctDNA and tissue testing within 2 months of each other, only one patient showed a similar MET alteration in the tissue. Six of the seven patients with only ctDNA positive for $M E T$ alterations had bone metastases. 
Table 3 Association with the number of alterations*

\begin{tabular}{|c|c|c|c|c|}
\hline Variables & $\begin{array}{l}\text { Median } N \text { of alterations } \\
(95 \% \mathrm{Cl}) \text { (range) }\end{array}$ & $\begin{array}{l}P \text { value } \\
\text { (univariable) }\end{array}$ & $\begin{array}{l}\text { t statistic } \\
\text { (multivariable) }\end{array}$ & $\begin{array}{l}P \text { value } \\
\text { (multivariable) }\end{array}$ \\
\hline Overall & $1(1-1)(0-26)$ & & & \\
\hline \multicolumn{5}{|l|}{ Tumor type } \\
\hline Gastrointestinal & $2(1-2)(0-26)$ & 0.031 & - & - \\
\hline Brain & $0(0-0)(0-5)$ & $<0.001$ & - & - \\
\hline Lung & $2(2-3)(0-21)$ & $<0.001$ & - & - \\
\hline \multicolumn{5}{|l|}{ Genomic alterations } \\
\hline MET & $4(3-6)(1-21)$ & $<0.001$ & 3.35 & 0.001 \\
\hline TP53 & $3(3-3)(1-21)$ & $<0.001$ & 6.86 & $<0.001$ \\
\hline EGFR & $3(3-4)(1-26)$ & $<0.001$ & - & - \\
\hline PIK3CA & $5(4-6)(1-26)$ & $<0.001$ & 7.31 & $<0.001$ \\
\hline BRAF & $5(4-6)(1-26)$ & $<0.001$ & 6.54 & $<0.001$ \\
\hline KRAS & $4(3-4)(1-26)$ & $<0.001$ & 6.01 & $<0.001$ \\
\hline MYC & $5(3-6)(2-7)$ & $<0.001$ & 2.70 & 0.007 \\
\hline Metastatic/recurrence at the time of blood draw & $2(1-2)(0-26)$ & $<0.001$ & - & - \\
\hline \multicolumn{5}{|l|}{ Metastatic sites } \\
\hline Lymph node & $2(2-3)(0-21)$ & $<0.001$ & 2.05 & 0.041 \\
\hline Bone & $2(2-3)(0-26)$ & $<0.001$ & - & - \\
\hline Liver & $2(2-3)(0-26)$ & $<0.001$ & - & - \\
\hline Lung & $2(1-3)(0-19)$ & 0.010 & - & - \\
\hline Brain & $2(1-3)(0-21)$ & $<0.001$ & - & - \\
\hline Adrenal & $2(2-4)(0-20)$ & $<0.001$ & 2.06 & 0.040 \\
\hline
\end{tabular}

*Only variables with $\geq 20$ patients in the overall population were tested. Only significant variables in the univariable analysis (non-parametric Mann-Whitney $U$ test) were included in the multivariable model (multiple linear regression), with the final model containing only significant covariates (stepwise model selection). The $t$ statistics test the unique contribution of each variable; the higher the $t$ statistics, the higher the association/contribution in the model

\section{Discussion}

This is the largest study interrogating the feasibility and utility of $M E T$ alteration detection through blood-derived ctDNA. Liquid biopsy is a non-invasive method to find genomic aberrations and is increasingly utilized in the clinical setting as reflected by the non-small cell lung cancer National Comprehensive Cancer Network (NCCN) guidelines $[18,19]$. Our study demonstrated that $M E T$ ctDNA alterations were detected in $7.1 \%$ of patients with solid tumors. This detection rate is higher compared to previous tissue studies [5, 20,21]. For instance, a study of $M E T$ tissue amplification determined by fluorescent in situ hybridization (FISH) demonstrated that $2.6 \%$ of 1115 solid tumor specimens were positive [5]. Furthermore, the MSKCC-IMPACT study showed that $3 \%$ of patients had $M E T$ tissue alterations [20,21]. The differences in rate of $M E T$ alterations between our study and the other studies could be due to following reasons: (i) our technology detected both single nucleotide substitutions and amplifications, while the previous investigation by Jardim et al. at MD Anderson Cancer Center [5] discerned only amplifications (though the MSKCC study would have discerned both single nucleotide substitutions and amplifications
[21]); (ii) our study used blood-derived ctDNA, which could capture shed tumor DNA from multiple sites, while the previous reports used tissue-based testing, which would only detect aberrations in the piece of tissue biopsied. Consistent with the above observations, our tissue NGS testing also showed significantly lower rates of $M E T$ alterations than the ctDNA NGS: 3 of 263 patients (1.1\%) (who also had ctDNA tests) were positive for $M E T$ alterations in tissue versus 31 of 438 ctDNA-tested patients (7\%) being positive for $M E T$ alterations $(P=0.0002)$. Further, of 18 patients positive for $M E T$ ctDNA alterations who also had tissue NGS, only 2 (11.1\%) were also positive for a $M E T$ alteration by tissue NGS. The biologic underpinnings of discordance between ctDNA and tissue NGS results have been previously documented and include spatial (intra-tumor and inter-tumor) and temporal heterogeneity in genomic anomalies in cancers along with the fact that ctDNA is comprised of DNA that has leaked into the circulation from diverse metastatic sites while tissue NGS reflects only the tissue specimen analyzed [14].

The question that arises is whether or not biological explanations can specifically account for the higher rate of $M E T$ alterations in ctDNA. Of interest in this regard, 
Table 4 Overall survival analysis $(N=438$ patients)*

\begin{tabular}{|c|c|c|c|c|c|}
\hline \multirow[b]{2}{*}{ Characteristics } & \multicolumn{2}{|l|}{ Univariable } & \multicolumn{3}{|c|}{ Multivariable } \\
\hline & Median time (months) (std. error) & $P$ value & Wald & $\begin{array}{l}\text { Hazard ratio } \\
\text { (Cl 95\%) }\end{array}$ & $P$ value \\
\hline \multicolumn{6}{|l|}{ Type of cancer } \\
\hline Gastrointestinal ( $n=123$ ) vs not & $36.3(4.5)$ vs $71.6(6.5)$ & 0.002 & - & - & - \\
\hline Brain $(n=109)$ vs not** & 95.0 (50.1) vs $51.5(5.9)$ & 0.003 & - & - & - \\
\hline Lung $(n=102)$ vs not & $31.8(6.0)$ vs $61.0(7.4)$ & 0.002 & 9.59 & $1.7(1.21-4.04)$ & 0.002 \\
\hline Breast $(n=51)$ vs not & $104.8(20.3)$ vs $50.0(5.6)$ & 0.027 & & & \\
\hline \multicolumn{6}{|l|}{ Genetic alteration type } \\
\hline $\operatorname{MET}(n=31)$ vs not & $30.6(6.2)$ vs $58.4(6.3)$ & 0.013 & - & - & - \\
\hline $\operatorname{TP53}(n=149)$ vs not & 42.1 (6.1) vs $66.5(10.3)$ & 0.003 & - & - & - \\
\hline PIK3CA $(n=42)$ vs not & 43.2 (10.6) vs (58.4 (6.3) & 0.013 & - & - & - \\
\hline ARID1A $(n=19)$ vs not & $24.8(6.2)$ vs $58.4(6.8)$ & 0.002 & 7.98 & $2.7(1.25-4.0)$ & 0.005 \\
\hline $\operatorname{KRAS}(n=50)$ vs not & $18.3(7.3)$ vs $59.7(6.5)$ & $<0.001$ & 15.68 & $2.1(1.5-3.12)$ & $<0.001$ \\
\hline $\operatorname{ALK}(n=14)$ vs not & $31.3(9.0)$ vs $58.3(6.7)$ & 0.015 & 5.76 & $2.04(1.14-3.7)$ & 0.016 \\
\hline SMAD4 $(n=12)$ vs not & $21.7(8.2)$ vs $58.3(6.2)$ & 0.007 & - & - & - \\
\hline MYC $(n=20)$ vs not & 22.2 (3.9) vs 59.1 (6.5) & $<0.001$ & 7.59 & $2.17(1.24-3.77)$ & 0.006 \\
\hline $\begin{array}{l}\text { Metastatic/recurrence at the time of } \\
\text { blood draw vs not }\end{array}$ & 53.6 (4.9) vs NR & 0.011 & - & - & - \\
\hline \multicolumn{6}{|l|}{ Metastatic sites } \\
\hline Liver $(n=111)$ vs not & 49.3 (8.2) vs 59.1 (7.9) & 0.023 & 4.85 & $1.4(1.03-1.89)$ & 0.028 \\
\hline Lymph node $(n=139)$ vs not & 39.9 (7.4) vs $74.1(11.1)$ & $<0.001$ & - & - & - \\
\hline
\end{tabular}

our study showed that bone metastases were independently correlated with $M E T$ alterations (Additional file 1: Table S2 and Table S4). Indeed, 14 of 31 patients (45\%) positive for $M E T$ ctDNA alterations had bone metastases (Additional file 1: Table S4). Of possible relevance in this regard, MET inhibitors are known to show efficacy in bone lesions [22, 23]. In the COMET-1 trial, 682 patients with castrate-resistant prostate cancer who progressed after docetaxel and androgen modulators (abiraterone and/or enzalutamide) were randomly assigned to either cabozantinib (MET inhibitor) or prednisone. Although there was no difference in overall survival, $42 \%$ of cabozantinib-treated patients showed bone scan response compared to $3 \%$ of prednisone-treated patients $(P<0.001)$, albeit without prostate surface antigen (PSA) response [24]. In the METEOR trial, 658 patients with advanced renal cell carcinoma who progressed with at least one VEGFR small molecule inhibitor were randomized to the MET inhibitor cabozantinib or the mTOR inhibitor everolimus [25]. In a sub-group analysis, patients randomized to cabozantinib arm with bone metastasis were associated with better overall survival (OS) (hazard ratio (HR) 0.54, 95\% confidence interval (CI) 0.34-0.84) compared with non-bone metastasis (HR 0.71, 95\% CI 0.55-0.91) [25]. These data together with our results raise the possibility that cancer clones with $M E T$ alterations preferentially localize to bone and may therefore explain bone responses after MET inhibitor therapy. Tissue biopsies are rarely performed on bones (none of our 18 patients with MET alterations in ctDNA who also had tissue NGS had a bone biopsy). Of interest in this regard, MET is prominently expressed (as determined by immunohistochemistry) at the site of bone metastases in renal cell cancer [26]. It is therefore conceivable that the high rates of ctDNA positivity for $M E T$ alterations, which strongly and independently correlated with bone metastases in our study, reflect shed $M E T$ alteration-bearing DNA from bone lesions (Additional file 1: Table S2 and Table S4).

Our study also found that $M E T$ ctDNA alterations are associated with poor prognosis, including decreased survival and shorter time to recurrence/metastasis (Tables 4 and 5, Fig. 1b). These results are consistent with those found by correlating $M E T$ alterations found in tissue NGS with outcome in specific malignancies, such as astrocytomas [27], breast cancers [28], genitourinary malignancies [29], and ovarian [30] or gastric/esophageal 
Table 5 Time to metastasis/recurrence from diagnosis $(N=438$ patients)*

\begin{tabular}{|c|c|c|c|c|c|}
\hline \multirow[b]{2}{*}{ Characteristics } & \multicolumn{2}{|l|}{ Univariable } & \multicolumn{3}{|c|}{ Multivariable } \\
\hline & Median time (months) (95\% Cl) & $P$ value & Wald & $\begin{array}{l}\text { Hazard ratio } \\
\text { (Cl 95\%) }\end{array}$ & $P$ value \\
\hline \multicolumn{6}{|l|}{ Type of cancer } \\
\hline Gastrointestinal ( $n=123$ ) vs not & $0.67(0-1.9)$ vs 14.1 (8.3-19.8) & $<0.001$ & - & - & - \\
\hline Brain $(n=109)$ vs not & $42.8(19.0-66.7)$ vs $2.5(0.49-4.4)$ & $<0.001$ & - & - & - \\
\hline Lung $(n=102)$ vs not & $0.6(0-1.3)$ vs $14.0(9.5-18.6)$ & $<0.001$ & - & - & - \\
\hline Breast $(n=51)$ vs not & $30.4(14.3-46.4)$ vs $7.0(3.8-10.2)$ & 0.001 & 40.03 & $0.33(0.23-0.47)$ & $<0.001$ \\
\hline Genitourinary $(n=18)$ vs not & 0 (-) vs $10.1(6.8-13.4)$ & 0.020 & - & - & - \\
\hline Head and neck $(n=10)$ vs not & 0 (-) vs $9.8(6.2-13.4)$ & 0.015 & - & - & - \\
\hline \multicolumn{6}{|l|}{ Genetic alteration type } \\
\hline $\operatorname{MET}(n=31)$ vs not & 1.0 (-) vs 10.4 (6.9-14.0) & 0.003 & 4.05 & $1.47(1.01-2.13)$ & 0.044 \\
\hline $\operatorname{TP53}(n=149)$ vs not & $4.1(0.5-7.7)$ vs $12.7(6.1-19.3)$ & 0.001 & - & - & - \\
\hline EGFR $(n=53)$ vs not & $3.6(0-8.2)$ vs $11.4(7.9-14.8)$ & 0.003 & - & - & - \\
\hline ARID1A $(n=19)$ vs not & $3.6(0-10.1)$ vs $10.0(6.3-13.7)$ & 0.013 & - & - & - \\
\hline KRAS $(n=50)$ vs not & 0 (-) vs $11.4(8.3-13.7)$ & $<0.001$ & - & - & - \\
\hline SMAD4 $(n=12)$ vs not & 0 (-) vs $10.1(6.7-13.4)$ & 0.040 & - & - & - \\
\hline MYC $(n=20)$ vs not & $0.2(0-0.75)$ vs $10.4(7.0-13.9)$ & $<0.001$ & - & - & - \\
\hline \multicolumn{6}{|l|}{ Metastatic sites } \\
\hline Adrenal $(n=29)$ vs not & 0 (--) vs 11.3 (8.0-14.6) & 0.002 & - & - & - \\
\hline Bone $(n=102)$ vs not & $1.5(0-6.7)$ vs $11.4(8.2-14.5)$ & 0.049 & - & - & - \\
\hline Liver $(n=111)$ vs not & 0.9 (0-2.6) vs $132.3(9.7-16.9)$ & $<0.001$ & 10.04 & $1.49(1.16-1.92)$ & 0.022 \\
\hline Lymph node $(n=139)$ vs not & 0.3 (-) vs 20.1 (14.3-25.9) & $<0.001$ & 13.41 & $1.54(1.22-1.92)$ & $<0.001$ \\
\hline Peritoneal $(n=49)$ vs not & 0 (-) vs $11.3(8.1-14.5)$ & $<0.001$ & - & - & - \\
\hline Brain $(n=63)$ vs not & $3.6(0-7.8)$ vs $10.4(7.0-13.9)$ & 0.045 & - & - & - \\
\hline Lung $(n=90)$ vs not & $1.2(0-8.0)$ vs $11.3(7.7-15.0)$ & 0.003 & - & - & - \\
\hline
\end{tabular}

The Wald statistics test the unique contribution of each variable; the higher the Wald statistics, the higher the association/contribution in the model ${ }^{*}$ Only variables that were significant in the univariable models (log rank test) were included in the multivariable analysis (Cox regression model), with the final model containing only significant covariates in the multivariable analyses (forward stepwise selection model). For some values, the $95 \% \mathrm{Cl}$ could not be computed (-)

cancers [31]. Specific genes that were co-altered with $M E T$ in multivariate analysis of our study participants include PTEN and TP53 (Table 2); previously, another study has also shown the association between $M E T$ and PTEN abnormalities [5]. Overall, MET alterations significantly correlated with a higher number of alterations, which may explain-at least in part-the relatively limited efficacy of MET inhibitors as single agents for the treatment of $M E T$-altered advanced malignancies observed in prior studies [5, 29-31]. Indeed, if patients with $M E T$ alterations generally have multiple genomic abnormalities, it is likely that combination therapy, rather than monotherapy with a MET inhibitor, may be necessary to achieve salutary effects.

Our study has several limitations. First, only $60 \%$ of our patients $(N=263)$ with ctDNA analyses also had tissue sequencing and the median time between the two tests in the patients with $M E T$-altered ctDNA was about 6 months. Second, our patients did not have bone biopsies done, which would be of interest to determine if
$M E T$ alterations are found in such biopsies, since ctDNA $M E T$ alterations correlate independently with the presence of bone metastases. Third, though our study with 438 patients is the largest to date, the rarity of $M E T$ alterations suggests that investigations of even greater numbers of patients may be worthwhile in order to best understand the biology and correlations of $M E T$ alterations.

\section{Conclusions}

In summary, our study demonstrated that assessment of $M E T$ genomic aberrations by liquid biopsy is feasible. We found that MET ctDNA anomalies were associated with bone metastases, multiple genomic alterations, and a poorer prognosis, including poorer overall survival and a shorter time to recurrence/metastases. Further studies are needed to better understand the biologic relationship between $M E T$ alterations and bone lesions, and next-generation trials with MET inhibitors may require combinations of drugs that address the genes such as PTEN that are frequently co-altered in these patients. 


\section{Additional file}

Additional file 1: Table S1. 54-gene panel ( $N=122$ patients) - identifies potential tumor-related genomic alterations within 54 cancer-related genes including amplifications in ERBB2, EGFR, and MET. Only non-synonymous alterations were analyzed. Table S2. 68-gene panel ( $N=272$ patients), comprising amplifications in 16 genes as well as some fusions and indels. Only non-synonymous alterations were analyzed. Table S3. 70-gene panel ( $N=22$ patients). Only non-synonymous alterations were analyzed. Table S4. Comparison of clinical characteristics in 438 patients with or without MET alterations (univariate analysis). (DOCX $20 \mathrm{~kb}$ )

\section{Abbreviations}

95\% Cl: 95\% confidence interval; CAP: College of American Pathologists; ctDNA: Circulating tumor DNA; FDA: Food and Drug Administration; FISH: Fluorescent in situ hybridization; GAB1: GRB2-associated binding protein 1; GRB2: Growth factor receptor-bound protein 2; HGF: Hepatocyte growth factor; HR: Hazard ratio; NCCN: National Comprehensive Cancer Network; NGS: Next-generation sequencing; NSCLC: Non-small cell lung cancer; OS: Overall survival; PREDICT: Profile Related Evidence Determining Individualized Cancer Therapy; VAF: Variant allele fraction

\section{Acknowledgments}

This work was supported in part by the Joan and Irwin Jacobs Fund philanthropic fund [no grant number is applicable-Razelle Kurzrock] and by the National Cancer Institute at the National Institutes of Health [grant P30 CA016672 (Razelle Kurzrock, rkurzrock@ucsd.edu)].

\section{Availability of data and materials}

All data generated or analyzed during this study are included in this published article [and its additional files].

\section{Authors' contributions}

SI, RK, and MS designed the study. MS analyzed the data to generate the results and created the figures and tables. SI and MS drafted the manuscript. All authors edited and approved the final manuscript.

\section{Ethics approval and consent to participate}

Not applicable

\section{Competing interests}

Dr. Razelle Kurzrock has research funding from Incyte, Genentech, Merck Serono, Pfizer, Sequenom, Foundation Medicine, and Guardant as well as consultant fees from Sequenom, LOXO, and Actuate Therapeutics. Dr. Kurzrock is also a consultant for Genentech. She also has an ownership interest in CureMatch, Inc. The other authors declare that they have no competing interests.

\section{Publisher's Note}

Springer Nature remains neutral with regard to jurisdictional claims in published maps and institutional affiliations.

\section{Author details}

'Department of Medicine, Center for Personalized Cancer Therapy, Division of Hematology/Oncology, University of California, San Diego, Moores Cancer Center, 3855 Health Sciences Drive, \#0658, La Jolla, CA 92093-0987, USA.

${ }^{2}$ Tokyo Medical and Dental University, Tokyo, Japan. ${ }^{3}$ Department of Clinical Oncology, Hospital Sirio Libanes, Sao Paulo, Brazil.

Received: 1 March 2018 Accepted: 26 April 2018

Published online: 04 June 2018

\section{References}

1. Cooper CS, Park M, Blair DG, Tainsky MA, Huebner K, Croce CM, et al. Molecular cloning of a new transforming gene from a chemically transformed human cell line. Nature 1984:311:b29-33.

2. Park M, Dean M, Kaul K, Braun MJ, Gonda MA, Vande WG. Sequence of MET protooncogene cDNA has features characteristic of the tyrosine kinase family of growth-factor receptors. Proc Natl Acad Sci U S A. 1987;84:6379-83.
3. Bottaro DP, Rubin JS, Faletto DL, Chan AM, Kmiecik TE, Vande Woude GF, et al. Identification of the hepatocyte growth factor receptor as the c-met proto-oncogene product. Science. 1991;251:802-4.

4. Birchmeier C, Birchmeier W, Gherardi E, Vande Woude GF. Met, metastasis, motility and more. Nat Rev Mol Cell Biol. 2003;4:915-25.

5. Jardim DLF, Tang C, Gagliato DDM, Falchook GS, Hess K, Janku F, et al. Analysis of 1,115 patients tested for MET amplification and therapy response in the MD Anderson Phase I Clinic. Clin Cancer Res. 2014;20:6336-45.

6. Schmidt L, Duh FM, Chen F, Kishida T, Glenn G, Choyke P, et al. Germline and somatic mutations in the tyrosine kinase domain of the MET proto-oncogene in papillary renal carcinomas. Nat Genet. 1997;16:68-73.

7. Kawakami H, Okamoto I, Okamoto W, Tanizaki J, Nakagawa K, Nishio K. Targeting MET amplification as a new oncogenic driver. Cancers. 2014;6:1540-52.

8. Madoz-Gúrpide J, Zazo S, Chamizo C, Casado V, Caramés C, Gavín E, et al. Activation of MET pathway predicts poor outcome to cetuximab in patients with recurrent or metastatic head and neck cancer. J Transl Med. 2015;13:282.

9. Kurzrock R, Sherman SI, Ball DW, Forastiere AA, Cohen RB, Mehra R, et al. Activity of XL184 (cabozantinib), an oral tyrosine kinase inhibitor, in patients with medullary thyroid cancer. J Clin Oncol. 2011;29:2660-6.

10. Shaw AT, Kim DW, Nakagawa K, Seto T, Crinó L, Ahn M-J, et al. Crizotinib versus chemotherapy in advanced ALK-positive lung cancer. N Engl J Med. 2013;368:2385-94

11. Ross C, Sai-Hong 1O, Shapiro G. Efficacy and safety of crizotinib in patients with advanced c MET-amplified non-small cell lung cancer (NSCLC). JCO. 2014;15:suppl 8001. Abstract. Available from: http://meetinglibrary.asco.org/ record/92507/abstract.

12. Schwaederle M, Patel SP, Husain H, Ikeda M, Lanman R, Banks KC, et al Utility of genomic assessment of blood-derived circulating tumor DNA (ctDNA) in patients with advanced lung adenocarcinoma. Clin Cancer Res. 2017:23:5101-11.

13. Kato S, Krishnamurthy N, Banks KC, De P, Williams K, Williams C, et al. Utility of genomic analysis in circulating tumor DNA from patients with carcinoma of unknown primary. Cancer Res. 2017;77:4238-46.

14. Schwaederle M, Husain H, Fanta PT, Piccioni DE, Kesari S, Schwab RB, et al. Use of liquid biopsies in clinical oncology: pilot experience in patients. Clin Cancer Res. 2016:22:5497-505.

15. Bidard F-C, Madic J, Mariani P, Piperno-Neumann S, Rampanou A, Servois V, et al. Detection rate and prognostic value of circulating tumor cells and circulating tumor DNA in metastatic uveal melanoma. Int J Cancer. 2014; 134:1207-13.

16. Schwaederle M, Husain H, Fanta PT, Piccioni DE, Kesari S, Schwab RB, et al. Detection rate of actionable mutations in diverse cancers using a biopsy-free (blood) circulating tumor cell DNA assay. Oncotarget. 2016; 7:9707-17.

17. Lanman RB, Mortimer SA, Zill OA, Sebisanovic D, Lopez R, Blau S, et al. Analytical and clinical validation of a digital sequencing panel for quantitative, highly accurate evaluation of cell-free circulating tumor DNA. PLoS One. 2015; 10:e0140712.

18. Kwapisz D. The first liquid biopsy test approved. Is it a new era of mutation testing for non small cell lung cancer? Ann Transl. 2017;Med5:46.

19. Chabon JJ, Simmons AD, Lovejoy AF, Esfahani MS, Newman AM, Haringsma $\mathrm{HJ}$, et al. Circulating tumour DNA profiling reveals heterogeneity of EGFR inhibitor resistance mechanisms in lung cancer patients. Nat Commun. 2016;7:11815

20. Cheng DT, Mitchell TN, Zehir A, Shah RH, Benayed R, Syed A, et al. Memorial Sloan Kettering-integrated mutation profiling of actionable cancer targets (MSK-IMPACT): a hybridization capture-based next-generation sequencing clinical assay for solid tumor molecular oncology. J Mol Diagn. 2015;17:251-64.

21. Zehir A, Benayed R, Shah RH, Syed A, Middha S, Kim HR, et al. Mutational landscape of metastatic cancer revealed from prospective clinical sequencing of 10,000 patients. Nat Med. 2017;23:703-13.

22. Graham TJ, Box G, Tunariu N, Crespo M, Spinks TJ, Miranda S, et al. Preclinical evaluation of imaging biomarkers for prostate cancer bone metastasis and response to cabozantinib. J Natl Cancer Inst. 2014;106:dju033.

23. McKay RR, Kroeger N, Xie W, Lee J-L, Knox JJ, Bjarnason GA, et al. Impact of bone and liver metastases on patients with renal cell carcinoma treated with targeted therapy. Eur Urol. 2014;65:577-84.

24. Smith M, De Bono J, Sternberg C, Le Moulec S, Oudard S, De Giorgi U, et al. Phase III study of cabozantinib in previously treated metastatic castrationresistant prostate cancer: COMET 1. J Clin Oncol. 2016;34:3005-13. 
25. Choueiri TK, Escudier B, Powles T, Tannir NM, Mainwaring PN, Rini Bl, et al. Cabozantinib versus everolimus in advanced renal cell carcinoma (METEOR) final results from a randomised, open-label, phase 3 trial. Lancet Oncol. 2016;17:917-27.

26. Mukai S, Yorita K, Kawagoe Y, Katayama Y, Nakahara K, Kamibeppu T, et al. Matriptase and MET are prominently expressed at the site of bone metastasis in renal cell carcinoma: immunohistochemical analysis. Hum Cell. 2015;28:44-50

27. Pierscianek D, Kim YH, Motomura K, Mittelbronn M, Paulus W, Brokinkel B, et al. MET gain in diffuse astrocytomas is associated with poorer outcome. Brain Pathol. 2013;23:13-8,

28. de Melo Gagliato D, Fontes Jardim DL, Falchook G, Tang C, Zinner R, et al. Analysis of MET genetic aberrations in patients with breast cancer at MD Anderson Phase I Unit. Clin Breast Cancer. 2014;14:468-74.

29. Jardim DLF, de Melo Gagliato D, Falchook G, Zinner R, Wheler JJ, Janku F, et al. MET abnormalities in patients with genitourinary malignancies and outcomes with c-MET inhibitors. Clin Genitourin Cancer. 2015;13:e19-26.

30. Tang C, Fontes Jardim DL, Falchook GS, Hess K, Fu S, Wheler JJ, et al. MET nucleotide variations and amplification in advanced ovarian cancer: characteristics and outcomes with c-Met inhibitors. Oncoscience. 2013;1:5-13.

31. Jardim DLF, Gagliato D de M, Falchook GS, Janku F, Zinner R, Wheler $J$ J, et al. MET aberrations and C-MET inhibitors in patients with gastric and esophageal cancers in a phase I unit. Oncotarget. 2014;5:1837-45.

Ready to submit your research? Choose BMC and benefit from:

- fast, convenient online submission

- thorough peer review by experienced researchers in your field

- rapid publication on acceptance

- support for research data, including large and complex data types

- gold Open Access which fosters wider collaboration and increased citations

- maximum visibility for your research: over $100 \mathrm{M}$ website views per year

At BMC, research is always in progress.

Learn more biomedcentral.com/submissions 